\title{
Phase Transitions During Continuous Heating of Martensitic CuAlMn Alloys
}

\section{J. Dutkiewicz and E. Cesari*}

Institute for Metal Res. Polish Acad. Sci., 30-059 Kraków, ul. Reymonta 25, Poland

* Physics Department, Univ. of Balearic Islands, Palma de Mallorca, Cra. de Valldemossa km 7.5, Spain

\begin{abstract}
Phase transitions in CuAlMn alloys containing up to 12 at\% $\mathrm{Mn}$ and 27 at\% $\mathrm{Al}$ continuously heated up to $550^{\circ} \mathrm{C}$ were studied using differential scanning calorimetry and transmission electron microscopy. Alloys containing less than 4.8 at\% Mn exhibit an exothermal heat effect in the range $280-380^{\circ} \mathrm{C}$ due to $\gamma_{2}$ precipitation. The additional endothermal peak above $500^{\circ} \mathrm{C}$ is caused by $\mathrm{DO}_{3}$ disordering. Alloys of intermediate $\mathrm{Mn}$ and $\mathrm{Al}$ content show only a reversible martensitic and ordering transformations during repeated cycling in the range -50 to $+550^{\circ} \mathrm{C}$. Alloys of higher $\mathrm{Mn}$ (6 - 12 at\%) and lower Al content exhibit a diffused exothermal peak in the range 320 $450^{\circ} \mathrm{C}$ due to bainitic transformation and a broad endothermal effect above $500^{\circ} \mathrm{C}$ due to $\mathrm{L}_{1} / \mathrm{DO}_{3}$ disordering. Bainitic plates possess $9 \mathrm{R}$ structure. They contain more $\mathrm{Cu}$ and less $\mathrm{Mn}$ and $\mathrm{Al}$ when compared to initial alloy compositions. Precipitates of $\gamma_{2}$ compositions lie close to its equilibrium phase limits.
\end{abstract}

\section{INTRODUCTION}

$\mathrm{CuAlMn}$ alloys have been shown to exhibit a shape memory effect comparable to that of $\mathrm{CuAlZn}$ and $\mathrm{CuAlNi}$ alloys [1-3]. Martensitic transformation temperatures are very sensitive upon an ageing treatment causing initialy their increase, then decrease [4-6]. This was explained as due to a change of matrix chemical composition $[4,5]$; however, increase of stresses and changes of ordering, particularly in the first ageing period seem to be also important [6,7]. Recent studies of the ordering transitions in CuAlMn alloys indicate a decrease of $\mathrm{DO}_{3} \rightarrow \mathrm{B} 2$ transition temperature with increasing manganese content [8]. Nakanishi et al [9] observed also an increase of the martensitic transformation temperatures accompanying a change of $\mathrm{Mn}$ site occupancy during ageing.

In alloys containing less than $5 \mathrm{wt} \% \mathrm{Mn} \gamma_{2}$ precipitation was observed, while with increasing $\mathrm{Mn}$ content formation of bainite ( $\left.\alpha_{1}^{\prime}\right)$ occured during isothermal ageing causing significant changes of the characteristic transformation temperatures and degradation of martensitic transformation, at final stages of ageing. Depending on the manganese and aluminium content the kinetics of precipitation is altered $[4,6,7]$. It is therefore of interest to know what is the effect of continuous heating on the precipitation and ordering changes in alloys with various $\mathrm{Mn}$ and $\mathrm{Al}$ content. 


\section{EXPERIMENTAL PROCEDURE}

The alloys were cast in an induction furnace under argon atmosphere. After homogenization treatment at $750^{\circ} \mathrm{C}$ they were hot rolled down to 2 and $0.1 \mathrm{~mm}$. The characteristic transformation temperatures were measured using a differential scanning calorimeter (DSC) Perkin-EImer DSC-4 at a heating/cooling rate of $20 \mathrm{~K} / \mathrm{min}$. Composition of alloys and $\mathrm{M}_{\mathrm{S}}$ temperatures are given in Table 1 . The alloys were quenched from $800^{\circ} \mathrm{C}$ into room temperature (RT) water except for alloys 1,4 and 5 which were quenched in water at $60^{\circ} \mathrm{C}$. Transmission analytical electron microscope Hitachi H-600 equipped with scanning attachment and Link detector was used for microstructure investigations. Thin foils were obtained by jet electropolishing in $\mathrm{CrO}_{3}$ saturated $\mathrm{H}_{3} \mathrm{PO}_{4}$ solution.

Table 1

\begin{tabular}{|c|c|c|c|c|}
\hline Alloy & $\mathrm{Cu}$ at\% & $\mathrm{Mn}$ at\% & $\mathrm{Al} \mathrm{at} \%$ & $\mathrm{M}_{\mathrm{S}}\left[{ }^{\circ} \mathrm{C}\right]$ \\
\hline 1 & 71.4 & 1.5 & 27.1 & 18 \\
\hline 2 & 70.0 & 2.9 & 27.1 & -59 \\
\hline $1 \mathrm{~A}$ & 68.5 & 4.8 & 26.7 & -136 \\
\hline 4 & 70.9 & 5.9 & 23.2 & 50 \\
\hline $1 \mathrm{~B}$ & 69.7 & 6.9 & 23.4 & -30 \\
\hline 5 & 70.5 & 9.0 & 20.5 & 5 \\
\hline $3 \mathrm{~B}$ & 69.6 & 12.1 & 18.3 & -145 \\
\hline
\end{tabular}

\section{RESULTS AND DISCUSSION}

Fig. 1 shows the DSC curves obtained during heating and cooling of alloys 1,2 and 1A (a) with low manganese content where $\gamma_{2}$ precipitation was expected to occur $[4,6,7]$ and of alloys $3 \mathrm{~B}$ and 5 (b) of high manganese content where formation of bainite was observed. There are two endothermal peaks, one due to a reverse martensitic transformation and another one (visible also for alloy $1 \mathrm{~A}$ ) due to $\mathrm{DO}_{3}$ disordering above $500^{\circ} \mathrm{C}$. All alloys show also one exothermal peak in the range $280-390^{\circ} \mathrm{C}$ likely due to $\gamma_{2}$ precipitation. Ordering and martensitic transformation are reversible and as such, both show reverse thermal effects during cooling. The temperatures of the ordering transformation lie close to that determined by Prado et al [8] from resistivity measurements.

A similar character possess DSC curves obtained for alloys $3 \mathrm{~B}$ and 5 (Fig. 1b) although the exothermal effect is broader and shifted to higher temperatures. It is likely caused by the bainite formation [6,7]. The peaks related to ordering and disordering near $500^{\circ} \mathrm{C}$ are much broader than in the case of Fig. la and even clearly splitted for atloy 3B with the highest Mn content. This may be caused by partial $\mathrm{DO}_{3}$ and $\mathrm{L}_{2}$ ordering at higher $\mathrm{Mn}$ content as suggested by Nakanishi et al based on ALCHEMI method [9]. Ordering occurs at lower temperatures when increasing Mn content in agreement with the data of Prado et al [8]. 

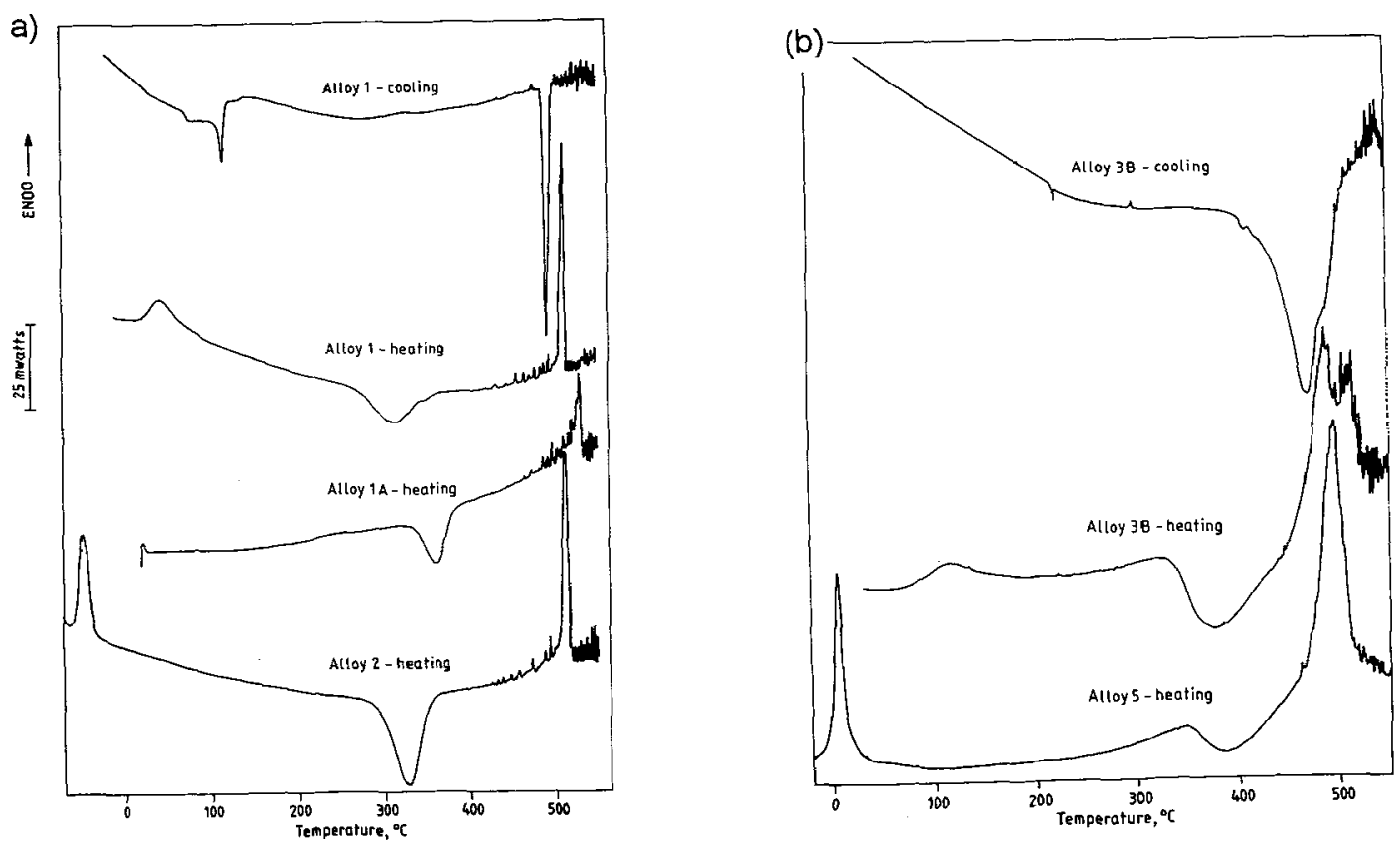

Fig. 1 DSC cooling/heating curves from alloys 1, 2 an $1 \mathrm{~A}$ (a) and 3B and 5(b)

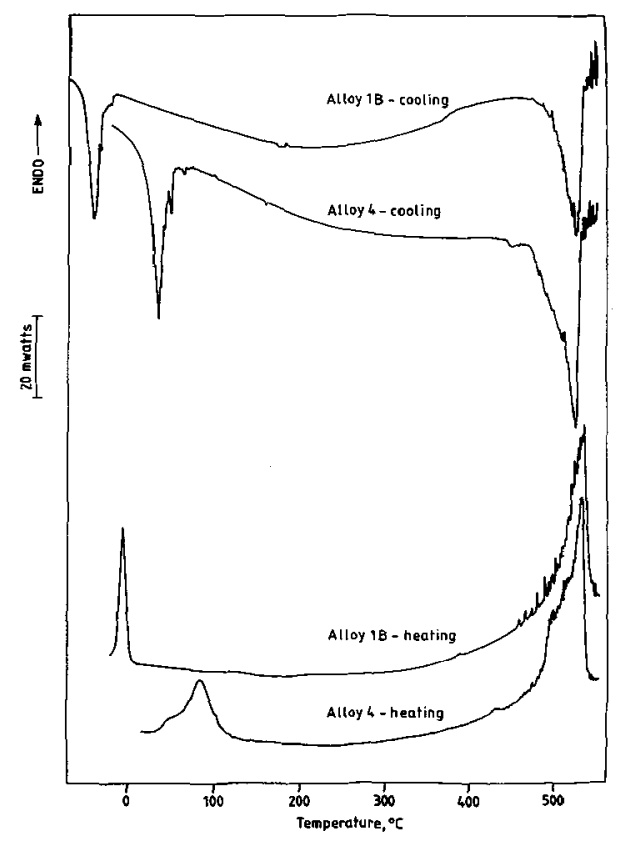

Fig. 2 DSC cooling/heating curves at $20 \mathrm{~K} / \mathrm{min}$ for alloys $1 \mathrm{~B}$ and 4.

DSC curves of alloys $1 \mathrm{~B}$ and 4 with intermediate $\mathrm{Mn}$ and $\mathrm{Al}$ content possess a different character. Contrary to the results presented in Fig. 1 no exothermal peak near $350^{\circ} \mathrm{C}$ can be seen on the heating curves. Peaks due to reversible transformations i.e. martensitic and ordering appear while heating and cooling also during repeated cycling. It results most probably from a low precipitation kinetics at this 
composition range as already suggested in [6]. Even heating/cooling at the rate $5 \mathrm{~K} / \mathrm{min}$ do not change this behaviour what suggest usefulness of these alloys for higher temperature applications.

Application of transmission analytical electron microscopy allowed to determine the character of composition changes after continuous heating up to the end of diffusional transformation. Precipitates of $\gamma_{2}$ show only a few percent composition difference with the matrix what explains a high density of precipitates after continuous heating up to the end of exothermal trasformation and the complete degradation of martensitic transformation. Fig. 3 shows the microstructure of alloy $3 \mathrm{~B}$ continuously heated up $10450^{\circ} \mathrm{C}$ i.e. to the end of bainitic trasformation. Microanalysis across the needle (marked by contamination spots) show an increase of $2 \mathrm{wt} \%$ of copper content and decrease of about 1 wt\% of $\mathrm{Mn}$ and $\mathrm{Al}$ content. For thicker plates this difference can be double as high.

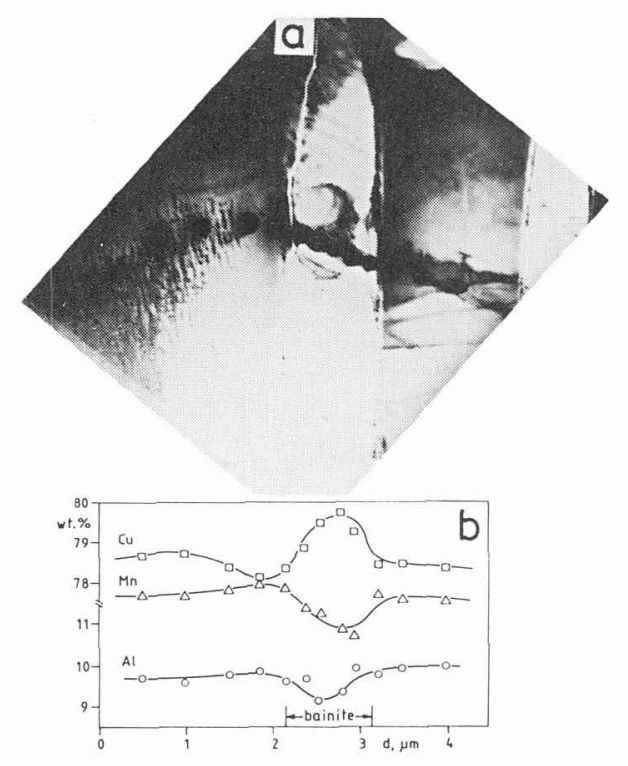

Fig. 3 Alloy $3 \mathrm{~B}$ continuously heated up to $450^{\circ} \mathrm{C}$ at the rate $20 \mathrm{~K} / \mathrm{min}$ :

(a) Transmission electron micrograph showig a bainitic needle with contamination spots.

(b) Corresponding change of $\mathrm{Cu}, \mathrm{Al}$ and Mn content across the bainitic needle.

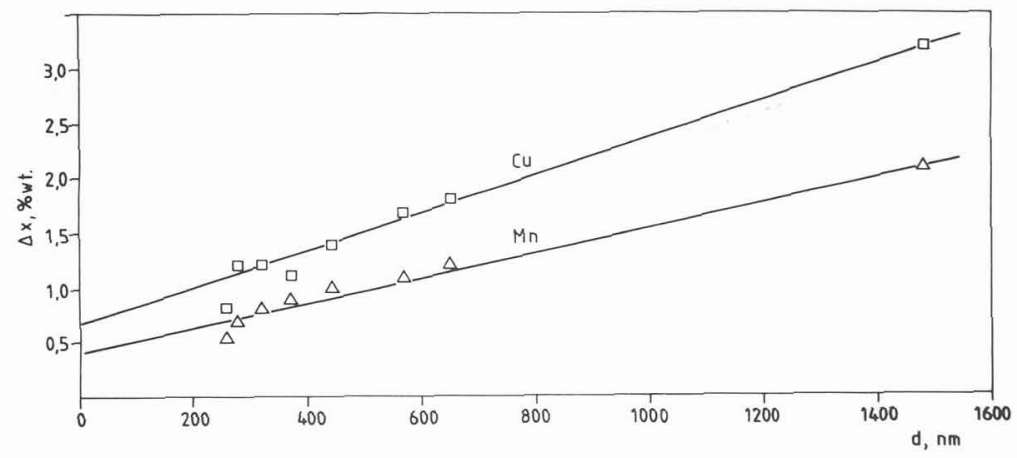

Fig. 4 composition difference between the bainite and the matrix as a function of a plate thickness. 
Fig. 4 shows the relationship between the $\Delta x$ (composition difference between the center of a bainitic plate and the matrix) and the plate thickness for alloy 5 continuously heated or isothermaly aged at $300^{\circ} \mathrm{C}$. It can be seen that $\Delta \mathrm{x}$ grows linearly with increasing plate thickness. Extrapolated value of $\Delta \mathbf{x}$ to 0 plate thickness do not approach to 0 composition difference. It may indicate that nucleation of bainite occurs with a certain composition difference. However, since the earliest nucleation stages were not observed, the participation of a shear mechanism cannot be excluded.

Fig. 5 shows a fragment of an isothermal section of the ternary CuAlMn system at $850^{\circ} \mathrm{C}$ with roughly marked estimated $M_{S}$ temperatures (by dotted lines) and positions of alloys investigated. Arrowheads point compositions of precipitating bainite or $\gamma_{2}$ phases (depending on what kind of precipitates form in a given alloy). Solid line arrows point compositions after continuous heating, while dotted line arrows after isothermal ageing at $300^{\circ} \mathrm{C}$. One can see that arrows coming out of alloy positions 1, 2 and $1 \mathrm{~A}$ are directed toward the center of $\gamma_{2}$ field, while those of alloys 5, 1B, 2B and 3B are pointing to the copper rich cormer. Compositions of bainite lie within the $\alpha+\beta$ phase field range; only in an extreme case of alloy 5 they are touching the $\alpha$-Cu phase field (not much shifted at lower temperatures [10]), but $\gamma_{2}$ compositions lie also outside the $\gamma_{2}$ phase range. Since this phase range shrinks at lower temperatures [10], it may be caused by an microanalysis error due to a small size of $\gamma_{2}$ precipitates what may influence the results by matrix radiation.

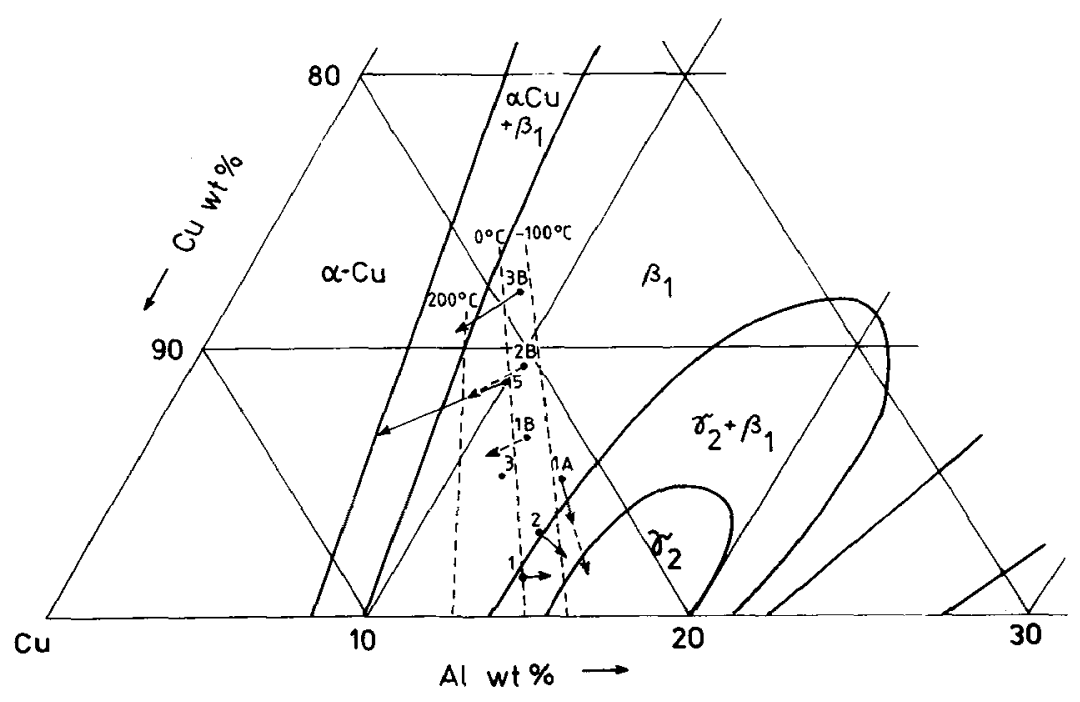

Fig. 5 Fragment of an isothermal section of the CuAlMn phase diagram at $850^{\circ} \mathrm{C}$ with marked investigated alloys and precipitating phases compositions. 


\section{CONCLUSIONS.}

1. Continuous heating of the CuAlMn alloys containing less than 4, 8 at $\%$ Mn causes $\gamma_{2}$ precipitation in the range $280-380^{\circ} \mathrm{C}$. It is connected with an exothermal heat effect. The additional endothermal peak above $500^{\circ} \mathrm{C}$ is due to $\mathrm{DO}_{3}$ disordering.

2. Continuous heating of alloys of higher Mn content (6-12 at\%) and lower $\mathrm{Al}$ content causes formation of a diffused exothermal peak in the range $320-450^{\circ} \mathrm{C}$ and a broad endothermal heat effect due to $\mathrm{DO}_{3} / \mathrm{L} 2_{1}$ disordering. At highest $\mathrm{Mn}$ content the disordering peak shows a clear splitting due to the separation of $\mathrm{DO}_{3}$ and $\mathbf{L} 2_{1}$ effects.

3. Alloys of intermediate $\mathrm{Mn}$ (5-6 at\%), and $\mathrm{Al}$ (23-24 at\%) content show only reversible martensitic and ordering transformations during repeated cycling in the range $-50 \leftrightarrow 550 \circ \mathrm{C}$ at the rates $5 \leftrightarrow 20 \mathrm{~K} / \mathrm{min}$.

4. The compositions of bainitic plates are shifted towards the copper rich corner in the ternary CuAlMn phase diagram, when compared to the initial alloy compositions being outside the equilibrium $\alpha$-Cu field. With increasing thickness of plates its composition difference with the matrix increases. Compositions of precipitating $\gamma_{2}$ phase lie close to its equilibrium phase limits.

\section{REFERENCES}

1. Lobodyuk V. A., Martynov V. V. Tkachuk V. R. and Khandros L. G., Metallofiz, 63 (1976) 55-59.

2. Mellor B. G., Hernáez J. and López del Castillo C., Scripta Met., 20 (1986) 839-841.

3. Counioux J., Maqueron J. L., Robin M. and Scarabello J. M., Scripta Met., 22 (1988) 821.

4. Matsushita K., Okamoto Takashi and Okamoto Taira, J. Materials Sci., 20 (1985) 689-699.

5. Bublei I. R., Efimova T. V., Lobodyuk V. A., Polotniuk V. V. and Titov P. V., Metallofiz., 11 (1989) 30-33.

6. Dutkiewicz J., Cesari E., Seguí C. and Pons J., J. de Physique., C4, 1 (1991) 229-234.

7. Dutkiewicz J., Pons J. and Cesari E., Materials Sci. Eng., A158 (1992) 119-128.

8. Prado M., Sade M. and Lovey F., Scripta. Met., et Mat. 28 (1993) 545-548.

9. Nakanishi N., Shigematsu T., N. Nachida, Ueda K., Shimizu K. and Nakata Y. ICOMAT 92, Monterey Inst. for Adv. Studies, CA 93921, USA, p.581-586.

10. Koester W and Goedeke T., Z. Metallkcle., 57 (1966) 889-901.

Acknowledgements. This work was partially supported by a Research Grant No 308499101 from the Polish State Committee for Scientific Research and by CICyT (Research Project MAT-93-0188). 